\title{
Vesicoureteral Reflux, a Scarred kidney, and Minimal Proteinuria: An Unusual Cause of Adult Secondary Hypertension
}

\author{
Shaifali Sandal and Apurv Khanna \\ Department of Medicine, SUNY Upstate Medical University, 343 CWB, 750 E. Adams, Syracuse, NY 13210, USA \\ Correspondence should be addressed to Apurv Khanna, khannaa@upstate.edu
}

Received 7 July 2011; Revised 10 September 2011; Accepted 18 September 2011

Academic Editor: Ron Rabinowitz

Copyright (๑) 2011 S. Sandal and A. Khanna. This is an open access article distributed under the Creative Commons Attribution License, which permits unrestricted use, distribution, and reproduction in any medium, provided the original work is properly cited.

\begin{abstract}
Hypertension affects about 65 million individuals in the United States. In adult patients, primary aldosteronism and renovascular causes are described as most prevalent. Vesicoureteral reflux as a cause of hypertension, while commonly described in pediatric populations, is less prevalent in the adult population especially in the absence of proteinuria. We present the case of a 31-year-old female presenting with early onset hypertension. Workup for renovascular hypertension was unrevealing. She was found to have right-sided vesicoureteral reflux with a unilateral scarred kidney. Patient underwent a nephrectomy with marked improvement in blood pressure control.
\end{abstract}

\section{Introduction}

The absolute number and percentage of adults with hypertension was estimated to be at least 65 million and $31.3 \%$, respectively, in the US from years 1999-2000 [1]. In the adult population, $5-10 \%$ cases of hypertension are identified to be due to secondary causes such as renal parenchymal disease from diabetes or hypertension, fibromuscular dysplasia, atherosclerotic disease, primary aldosteronism, pheochromocytoma, Cushing's disease, hypo/hyperthyroidism, hyperparathyroidism, and obstructive sleep apnea [2].

Vesicoureteral reflux (VUR) is a less recognized cause of hypertension in the adult population. It is a congenital anomaly of the ureterovesical junction due to deficiency of the submucosal longitudinal muscle that predisposes the individual to retrograde urine reflux. Adult presentation of primary VUR occurs in patients who have had VUR since childhood that has remained undetected and presents in adulthood with complications or patients who develop VUR in adulthood de novo with no prior history of UTI [3]. Primary VUR occurs in the absence of any underlying pathology, while secondary VUR in the adult occurs due to conditions such as obstruction, previous surgical procedures, or a neurological disorder [3]. Long-term sequalae include end-stage renal disease, proteinuria, hypertension, urinary tract infections, and renal calculi [3-5]. Incidence of hypertension in adults with reflux nephropathy has been reported to be anywhere between 38-60\% [4-9] often associated with proteinuria. We present a case of a 31-year-old female who had right-sided VUR with a scarred right kidney as the cause of her underlying hypertension.

\section{Case Presentation}

A 31-year-old female with onset of hypertension in adolescence initially presented to us with a recent history of hypertensive urgency and prior history of systolic blood pressure of $220 \mathrm{~mm}$ of Hg. She had been started on Amlodipine $10 \mathrm{mg}$ once daily by her primary care physician and referred to the University Nephrology Clinic. Past medical history was significant for workup for secondary hypertension through a local nephrology practice approximately nine years ago. At that time, renal artery stenosis was considered the most likely diagnosis and was pursued with invasive testing. She underwent a renal arteriogram at that time which did not reveal stenosis. Careful history by us, however, revealed recurrent urinary tract infections and back pain accompanying these episodes which aroused our suspicion for a diagnosis of pyelonephritis and vesicoureteral reflux. 
Her family history was significant for middle age onset of primary hypertension in her father; her mother was diagnosed with autosomal dominant polycystic kidney disease leading to end-stage renal disease. She was sexually active with no use of oral contraceptives. On presentation to us, her physical examination revealed blood pressure of $153 / 97 \mathrm{mmHg}$, equal in both arms, and with strong pulses in upper and lower extremities. The remainder of the physical examination was essentially unremarkable; no femoral, carotid, or abdominal bruits were appreciated.

Urinalysis revealed 2+ leukocyte esterase, positive for nitrites, trace protein, trace blood, and white blood cell count of 47. Her complete blood count and basic metabolic panel were unremarkable. Serum creatinine was $0.7 \mathrm{mg} / \mathrm{dL}$, and 24 -hour urine protein was $0.24 \mathrm{gm} / 24$ hours $(<0.2 \mathrm{gm} / 24$ hours).

Ultrasound of the kidneys showed a right kidney measuring $7.8 \mathrm{~cm}$ with severe cortical thinning and the left kidney measuring $13.2 \mathrm{~cm}$ with normal cortical echogenicity. There was no evidence of hydronephrosis or renal calculi. Realtime sonographic, duplex, and color Doppler images of the kidneys demonstrated a scarred right kidney. Doppler of renal arteries did not show renal artery stenosis. A voiding cystourethrogram demonstrated grade- 3 , right vesicoureteral reflux. There was also focal narrowing of the right ureterovesical junction. The bladder was within normal limits. Nuclear imaging to evaluate renal flow showed prompt radiopharmaceutical uptake within the left kidney. The right kidney was not clearly visualized on flow phase or functional images. On delayed imaging, there was reflux into the right collecting system.

She was started on hydrochlorothiazide $25 \mathrm{mg}$ once daily by mouth. Angiotensin converting enzyme inhibitors were not used due to the patient being sexually active without use of contraception. Subsequently, surgical opinion was sought regarding possible nephrectomy. The patient underwent a laparoscopic right nephrectomy and partial ureterectomy successfully. Microscopic analysis of the kidney revealed chronic pyelonephritis and extensive cortical atrophy. At four month followup, the patient demonstrated excellent blood pressure control at $118 / 88 \mathrm{~mm}$ of $\mathrm{Hg}$ while maintained on hydrochlorothiazide $12.5 \mathrm{mg}$ once daily by mouth.

\section{Discussion}

3.1. VUR and Hypertension in Children. Secondary hypertension is more common in the pediatric population. 60 $80 \%$ of secondary hypertension is caused by renal parenchymal disease [10]. VUR, multicystic dysplastic kidney, ureteropelvic junction obstruction, and posterior urethral valves have been associated with hypertension [11]. VUR is one of the most common causes of severe hypertension in children $[6,10-13]$.

VUR was noted in $29 \%$ to $50 \%$ of children with UTIs, often the initial presentation [14]. The prevalence of hypertension in children with primary vesicoureteral reflux was estimated to increase with age: it was $1.7 \%$ for patients aged 1 year to 9.9 years, $1.8 \%$ for adolescents aged 10 years to
14.9 years, $4.7 \%$ for patients aged 15 years to 19.9 years, and $35 \%$ for patients $>20$ years of age [15]. It was estimated that $50 \%$ of patients with unilateral and bilateral renal damage would be hypertensive at about 30 and 22 years of age, respectively [15]. Hypertension was strongly associated with renal scarring, and VUR increases renal scarring $[6,15]$.

3.2. VUR and Hypertension in Adults. Incidence of hypertension in adults with reflux nephropathy has been reported to be anywhere between 38-60\% [4-9]. A retrospective study reported nearly $60 \%$ of patients with VUR had hypertension at presentation; it was significantly associated with the presence of $>1 \mathrm{~g} /$ day of proteinuria, although the exact number of patients who had both proteinuria and hypertension was not reported [5]. Studies have reported an inherent relationship between hypertension and proteinuria in patient who have VUR [9]. This was not the case with our patient. Our patient had a 24 -hour urine protein of $0.24 \mathrm{gm} / 24$ hours.

To our knowledge, only one study in adults so far has reported serious consideration of VUR as a secondary cause hypertension in the absence of renal injury markers. In a study by Barai et al., 19.1\% of adult patients with hypertension who do not have any evidence of renal involvement had VUR and are often labeled as having essential hypertension [16]. An editorial did criticize this study as none of the patients had frequent UTI's, an inherent selection bias may have existed as none of the patients had an indication to have a direct radionuclide voiding cystoscintigraphy (DRVC) performed, and, lastly, that no imaging study was performed to evaluated renal scarring [17]. For our patient, we performed a real-time sonographic, duplex, and color doppler images of the kidneys which did reveal a scared right kidney.

3.3. Cause. In the absence of proteinuria, the underlying cause of how VUR and a scarred kidney cause hypertension is unclear. Past studies have suggested that reflux nephropathy can activate the renin angiotensin system. In children, it has been shown that patients with VUR have high circulating or selective renal vein renin levels [10]. One study suggested no consistent evidence to support the role of reninangiotension and hypertension in patients with unilateral reflux nephropathy [18]. Another study showed upregulation of angiotensin II receptors in reflux nephropathy [19]. While one study from Spain showed genetic polymorphisms of renin-angiotensin-aldosterone (RAS) components are not independent prognostic indicators of renal scarring in patients with VUR [20], another study from Taiwan showed that angiotensin-converting enzyme gene polymorphisms were associated with progressive renal deterioration in Taiwanese children with VUR [21].

3.4. Diagnosis. Guidelines for diagnosis of VUR in the adult population have been devised with reference to the screening for VUR in the pediatric population [3]. A recent review article stated that voiding cystourethrography is the gold standard in reflux diagnosis in the pediatric population [22]. Renal sonography is often recommended as the initial 
evaluation followed by micturating cystourethrogram, radionuclide cystography, intravenous pyelography, ultrasound, CT, and MRI [3]. Barai et al. did mention that, in patients who do not have any signs of renal parenchymal and renovascular injury as demonstrated by negative serum creatinine, captopril renography, and urinalysis for proteinuria, studies such as DRVC should be included as part of a workup for VUR [16]. They, however, recommended further retrospective studies prior to making DRVC as standard of care in looking for underlying causes of hypertension.

3.5. Treatment. Treatment options can be surgical or medical. Medical treatment consists of antimicrobial treatment or prophylaxis of UTI and treatment of hypertension; however, long-term antibiotic prophylaxis may not be an ideal option for a younger patient in whom more definitive treatment would be preferred [3].

Surgical options have been well studied in the pediatric population. Primary ureteral reimplantation, extravesical and intravesical surgical techniques, ureteroneocystotomy, and endoscopic subureteral injections are some of the techniques employed in the correction of VUR in the pediatric population with success rates of $92-98 \%$ [23]. In adults, some studies have reported endoscopic correction using polytetrafluoroethylene (Teflon) or dextranomer/hyaluronic acid copolymer [24], endoscopic trigonoplasty [25], or endoscopic subureteral glutaraldehyde cross-linked collagen injection [26].

The only two indications for surgical correction of unilateral reflux in adults are a history of pyelonephritis with unsuccessful medical treatments or in women of childbearing age [27]. Recent studies, however, indicate that pregnant women with low-grade VUR and unscarred kidneys did not have any significant complications except a higher incidence of urinary tract infection, which was not modified by ureteric reimplantation [28]. Surgery, however, has been reported to have no beneficial effect on hypertension [29]. A randomized control trial failed to support the claim that renal function is improved by surgical correction of VUR in children with bilateral disease [30]. No recommendations exist for treatment specifically for hypertension in patients with VUR.

\section{Conclusion}

Our patient's workup was significant for recurrent urinary tract infections, grade 3 vesicoureteral reflux, minimal proteinuria, and a scarred kidney. Ultrasound with Doppler and voiding cystourethrogram were used for diagnosis. Medical treatment was not an ideal option in our young patient of child bearing age. A nephrectomy was performed primarily for persistent hypertension felt to be secondary to the unilaterally scarred kidney. After nephrectomy, our patient demonstrated markedly improved blood pressure control.

Through this case we hope to highlight VUR as a cause of secondary hypertension. Markers of renal injury such as elevated creatinine and proteinuria may be absent; however, a scarred kidney probably is the cause of patient's hypertension through an unknown mechanism. Medical management may not be ideal, and stenting is not the optimal treatment for a scarred kidney. Nephrectomy may be therapeutic in these cases. The long-term benefits remain to be seen, and randomized control trials are needed to study the efficacy of surgical versus medical management of VUR in the adult population.

\section{References}

[1] L. E. Fields, V. L. Burt, J. A. Cutler, J. Hughes, E. J. Roccella, and P. Sorlie, "The burden of adult hypertension in the United States 1999 to 2000: a rising tide," Hypertension, vol. 44, no. 4, pp. 398-404, 2004.

[2] S. J. Taler, "Secondary causes of hypertension," Primary Care, vol. 35, no. 3, pp. 489-500, 2008.

[3] O. Buckley, T. Geoghegan, J. O’Brien, and W. C. Torreggiani, "Vesicoureteric reflux in the adult," British Journal of Radiology, vol. 80, no. 954, pp. 392-400, 2007.

[4] Y. Zhang and R. R. Bailey, "A long term follow up of adults with reflux nephropathy," New Zealand Medical Journal, vol. 108, no. 998, pp. 142-144, 1995.

[5] V. Sakhuja, T. Muthukumar, K. Sud et al., "Vesicoureteric reflux and reflux nephropathy as seen at a tertiary care adult nephrology service in India- an analysis of 86 patients," Renal Failure, vol. 25, no. 2, pp. 173-181, 2003.

[6] C. D. Goonasekera and M. J. Dillon, "Hypertension in reflux nephropathy," British Journal of Urology International, vol. 83, supplement 3, pp. 1-12, 1999.

[7] S. H. Jacobson, O. Eklöf, C. G. Eriksson, L. E. Lins, B. Tidgren, and J. Winberg, "Development of hypertension and uraemia after pyelonephritis in childhood: 27 year follow up," British Medical Journal, vol. 299, no. 6701, pp. 703-706, 1989.

[8] V. E. Torres, R. S. Malek, and J. P. Svensson, "Vesicoureteral reflux in the adult. II. Nephropathy, hypertension and stones," Journal of Urology, vol. 130, no. 1, pp. 41-44, 1983.

[9] M. T. El-Khatib, G. J. Becker, and P. S. Kincaid-Smith, "Reflux nephropathy and primary vesicoureteric reflux in adults," Quarterly Journal of Medicine, vol. 77, no. 284, pp. 1241-1253, 1990.

[10] S. M. Bartosh and A. J. Aronson, "Childhood hypertension. An update on etiology, diagnosis, and treatment," Pediatric Clinics of North America, vol. 46, no. 2, pp. 235-252, 1999.

[11] S. B. Farnham, M. C. Adams, J. W. Brock, and J. C. Pope, "Pediatric urological causes of hypertension," Journal of Urology, vol. 173, no. 3, pp. 697-704, 2005.

[12] M. Y. Arar, R. J. Hogg, B. S. Arant Jr., and M. G. Seikaly, "Etiology of sustained hypertension in children in the southwestern United States," Pediatric Nephrology, vol. 8, no. 2, pp. 186-189, 1994.

[13] M. J. Dillon, "Investigation and management of hypertension in children. A personal perspective," Pediatric Nephrology, vol. 1, no. 1, pp. 59-68, 1987.

[14] "Medical versus surgical treatment of primary vesicoureteral reflux: report of the International Reflux study Ccommittee," Pediatrics, vol. 67, no. 3, pp. 392-400, 1981.

[15] A. C. Simoes e Silva, J. M. P. Silva, J. S. S. Diniz et al., "Risk of hypertension in primary vesicoureteral reflux," Pediatric Nephrology, vol. 22, no. 3, pp. 459-462, 2007.

[16] S. Barai, G. P. Bandopadhayaya, D. Bhowmik et al., "Prevalence of vesicoureteral reflux in patients with incidentally diagnosed adult hypertension," Urology, vol. 63, no. 6, pp. 10451048, 2004. 
[17] P. J. Scheel, "Prevalence of vesicoureteral reflux in patients with incidentally diagnosed adult hypertension: editorial comment," Urology, vol. 63, no. 6, pp. 1048-1049, 2004.

[18] R. R. Bailey, C. U. McRae, and T. M. J. Maling, "Renal vein renin concentration in the hypertension of unilateral reflux nephropathy," Journal of Urology, vol. 120, no. 1, pp. 21-23, 1978.

[19] B. Chertin, U. Rolle, S. Cascio et al., "Upregulation of angiotensin II receptors in reflux nephropathy," Journal of Pediatric Surgery, vol. 37, no. 2, pp. 251-255, 2002.

[20] R. Pardo, S. Málaga, E. Coto et al., "Renin-angiotensin system polymorphisms and renal scarring," Pediatric Nephrology, vol. 18, no. 2, pp. 110-114, 2003.

[21] K. P. Liu, C. Y. Lin, H. J. Chen, C. F. Wei, and G. J. Lee-Chen, "Renin-angiotensin system polymorphisms in Taiwanese primary vesicouretenal reflux," Pediatric Nephrology, vol. 19, no. 6, pp. 594-601, 2004.

[22] B. W. Snow and M. B. Taylor, "Non-invasive vesicoureteral reflux imaging," Journal of Pediatric Urology, vol. 6, no. 6, pp. 543-549, 2010.

[23] A. Heidenreich, E. Ozgur, T. Becker, and G. Haupt, "Surgical management of vesicoureteral reflux in pediatric patients," World Journal of Urology, vol. 22, no. 2, pp. 96-106, 2004.

[24] A. Natsheh, O. Z. Shenfeld, A. Farkas, and B. Chertin, "Endoscopic treatment of vesicoureteral reflux in an adult population: can we teach our adult urology colleagues?" Journal of Pediatric Urology, vol. 6, no. 6, pp. 600-604, 2010.

[25] K. Okamura, N. Kato, Y. Tsuji, Y. Ono, and S. Ohshima, "A comparative study of endoscopic trigonoplasty for vesicoureteral reflux in children and in adults," International Journal of Urology, vol. 6, no. 11, pp. 562-566, 1999.

[26] K. Inoue, T. Nakamoto, A. Usui, and T. Usui, "Endoscopic subureteral glutaraldehyde cross-linked collagen injection for the treatment of secondary vesicoureteral reflux: comparison with primary vesicoureteral reflux in adults," Journal of Urology, vol. 164, no. 2, pp. 336-339, 2000.

[27] D. A. Guthman, R. S. Malek, R. J. Neves, and J. Svensson, "Vesicoureteral reflux in the adult. V. Unilateral disease," Journal of Urology, vol. 146, no. 1, pp. 21-23, 1991.

[28] J. G. Hollowell, "Outcome of pregnancy in women with a history of vesico-ureteric reflux," British Journal of Urology International, vol. 102, no. 7, pp. 780-784, 2008.

[29] R. S. Malek, J. Svensson, R. J. Neves, and V. E. Torres, "Vesicoureteral reflux in the adult, III. Surgical correction: risks and benefits," Journal of Urology, vol. 130, no. 5, pp. 882-886, 1983.

[30] J. M. Smellie, T. M. Barratt, C. Chantler et al., "Medical versus surgical treatment in children with severe bilateral vesicoureteric reflux and bilateral nephropathy: a randomised trial," The Lancet, vol. 357, no. 9265, pp. 1329-1333, 2001. 


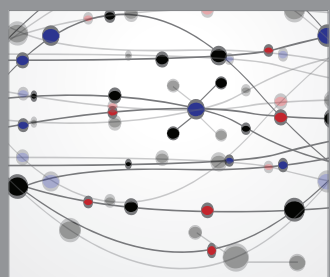

The Scientific World Journal
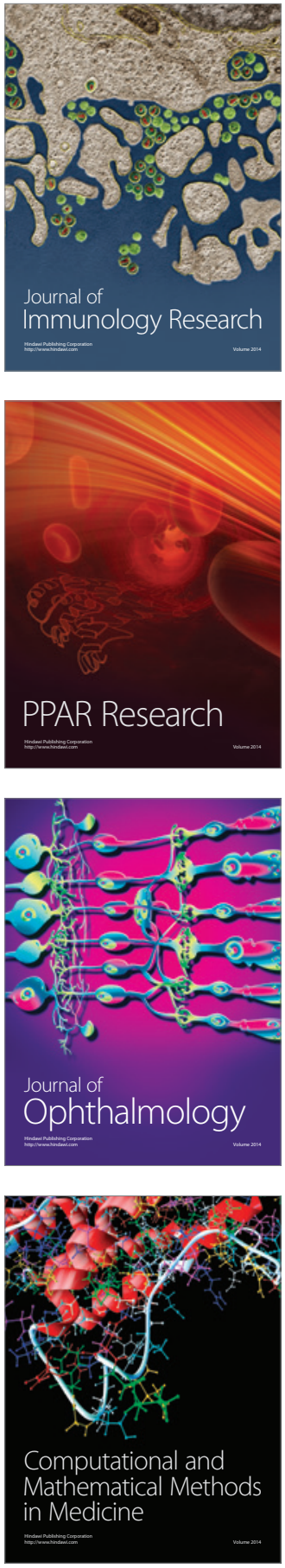

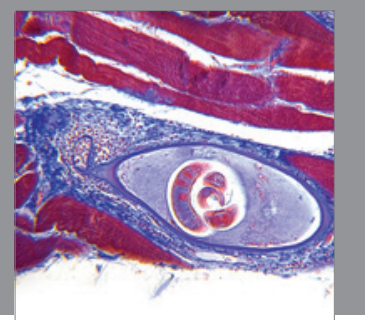

Gastroenterology

Research and Practice
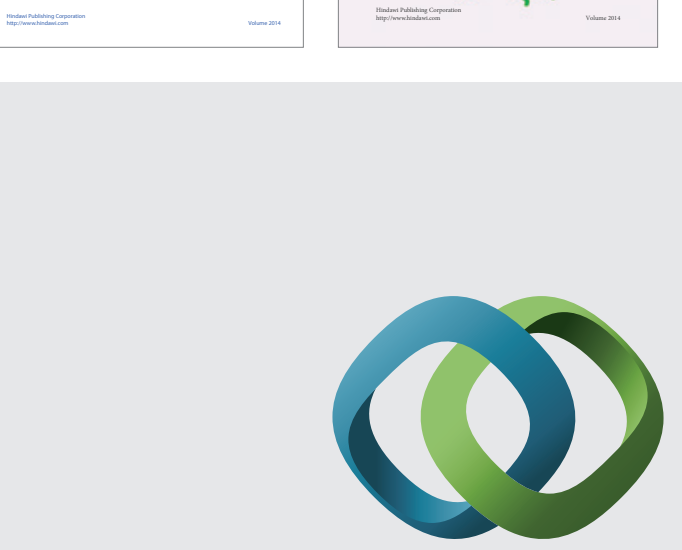

\section{Hindawi}

Submit your manuscripts at

http://www.hindawi.com
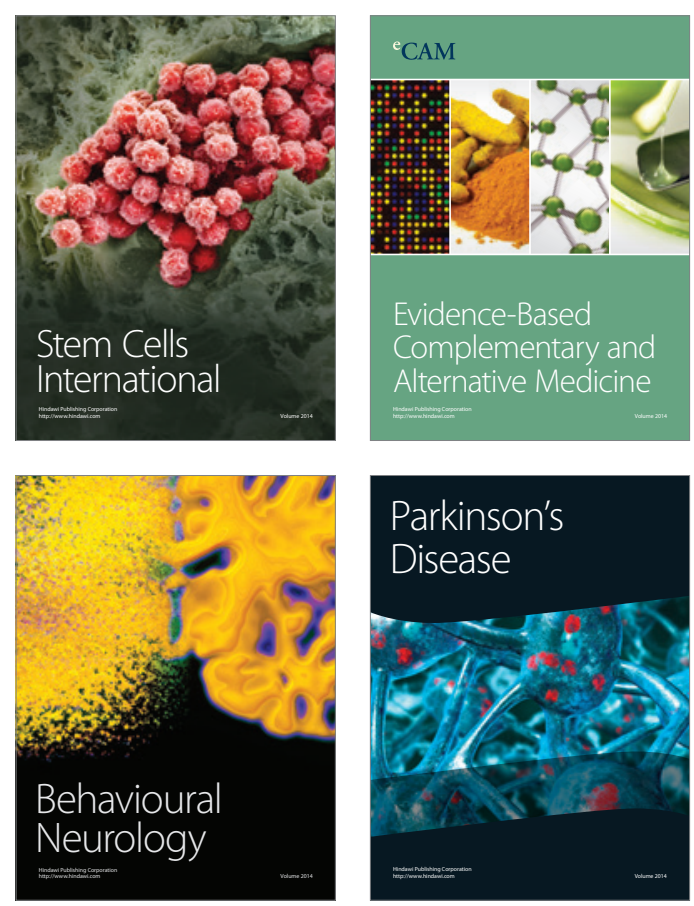

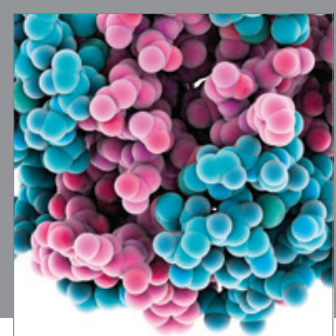

Journal of
Diabetes Research

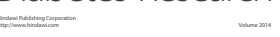

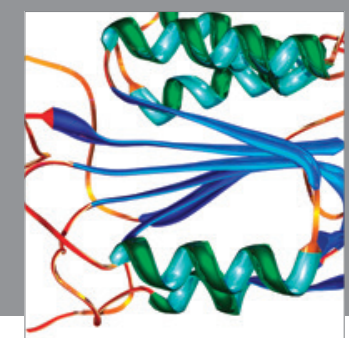

Disease Markers
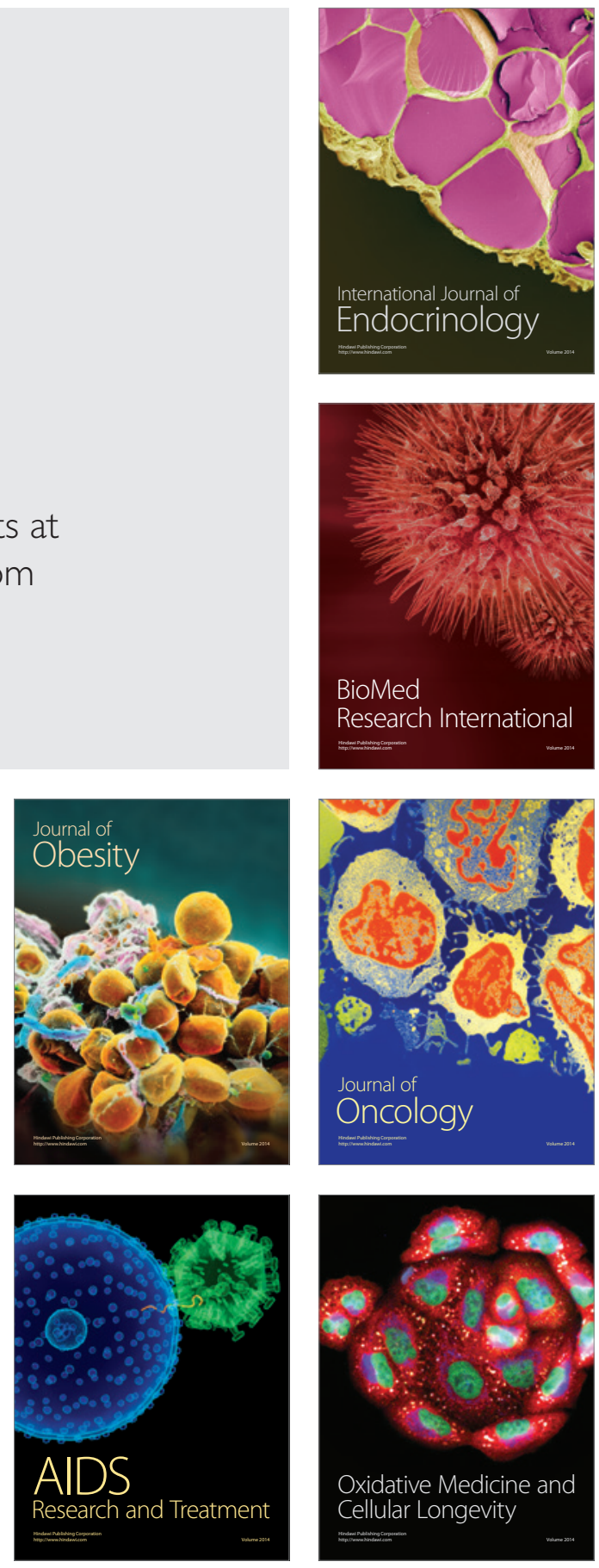